\title{
Analysis of the Optimization and Upgrading of Agricultural Industry in Weinan under the View of the Supply Side Reform
}

\author{
Ma Suying \\ Weinan Normal University, Weinan, Shaanxi, 714099
}

Keywords: Supply-Side Structural Reforms, Agricultural Industrial Structure, Contiguous Modern Food Base in the Whole Town, Main Body of New-Type Agricultural Operations, Integration and Development of Agriculture, Secondary and Tertiary Industries

\begin{abstract}
This paper uses the idea of the structural reform of the supply side to analyze the problems existing in the industrial structure of Weinan. With the theory of economics analysis of construction industry optimization, it is recommended to Weinan natural conditions, agricultural history as the starting point; to market demand, adjust the industrial structure and product structure; to speed up scientific and technological guidance and support of science and technology, expand the whole town contiguous modern grain base; improve regional agricultural scale level, let the market demand and production of agricultural products the relative access, realize the transition to the quality and efficiency of agricultural production. Taking the modern agricultural management system as the leading role and the modern animal husbandry demonstration area as the carrier, we should speed up the development of modern animal husbandry, accelerate the integration of agriculture into the two or three industry, and put forward feasible proposals for the sustainable development of Weinan's agricultural economy.
\end{abstract}

\section{Introduction}

In November 10, 2015, the eleventh meeting of the central economic and economic leadership group was held. At this meeting, general secretary Xi Jinping emphasized that, while expanding the total demand, we should focus on strengthening the structural reform of the supply side, and strive to improve the quality and efficiency of the supply system. This is the first time to put forward the idea of institutional reform on the supply side [1].

From the perspective of supply side, the driving factors of traditional agriculture such as labor and land are decreasing. The decrease of demographic dividend and the emergence of rural hollow villages make the marginal benefit of traditional agriculture decreasing. In the economic development of the new normal, agricultural economic growth must rely on in the adjustment and integration of the industrial structure, the industrial structure adjustment, is the integration of agriculture, the two or three industry development, technology oriented, realize large-scale and fine agriculture; to enhance the quality of the number instead of growth, conflicts of agricultural products supply and demand guide the agricultural, diversified and multi-level production, "the people's increasing need to better life" [2-3].

\section{Structural Reform of Agricultural Supply Side}

The core of the reform of the agricultural supply side is to adjust the production of products, including quality and quantity, to meet the needs of consumers and realize the seamless connection between the producing areas and the consumption areas through the adjustment of their own efforts.

The current agriculture faces many contradictions and problems, such as in food production appears strange phenomenon of birth yield, import volume, inventory three volume increase; on the one hand, farmers are difficult to sell agricultural products, product backlog, and even a lot of damage, drained problems; the one hand our country in a large number of consumers to buy milk powder and fruit from overseas phenomenon. The tragedy of the farmer's bumper harvest is constantly on, and the contradiction between supply and demand and the butt of supply and demand 
are not smooth. The high cost of grain production in China does not have a competitive advantage abroad, and the more production is increasing, the more losses are. The root cause lies in the structure of our country agriculture and agricultural policy [4]. To deepen the supply side structure reform, we must adjust the agricultural structure to improve the supply efficiency of agricultural products, enhance the allocation of agricultural resources in the market, promote the quality and efficiency of agricultural production, and solve the dilemma of China's agricultural development.

The domestic scholar Wu Jinming and Wang Tianliang pointed out that our country agriculture industry structure evolution direction from the traditional to the modern concept of grain food concept, the traditional planting structure of two yuan to three yuan structure of grain crops, economic crops and feed crops, the transformation from traditional agricultural products processing industry to modern food manufacturing industry shift from relying on the cultivated land to land resources opening and utilization of transition from resource type industry focus on the material input to the material input and intellectual input knowledge industry transformation and. Huang Zongzhi believes that China is experiencing a "recessive agricultural revolution", an evolution of agricultural structure driven by the market demand of high-value agricultural products, such as fish, meat, eggs, milk, vegetables and fruits. Li Bingkun pointed out that the evolution of the industrial structure of agriculture is an agricultural product quality rate to meet the changing process of agricultural product market demand, through the optimization of the ecological environment, follow the agricultural structural adjustment of regional advantages, improve agricultural systems to ensure that the benefits of agricultural industrial structure evolution.

\section{A Summary of the Current Situation of the Development of Agricultural Industry in Weinan}

Through the construction of agricultural park in Weinan, the new carrier of modern agriculture has been initially constructed, and the new pattern of modern agriculture has been continuously optimized by adjusting the industrial structure. The highlights of the agricultural work show 7 highlights:

\subsection{The situation of agricultural production continues to be better, and the industrial structure has gradually improved its benefit.}

The city's grain is expected to achieve "Twelve consecutive peaks", and the total output is stable at more than 2 million tons, achieving "stable output", "storing grain in the land" and "storing grain in technology". "12th Five-Year" period, affecting food production, reduce the sown area of frequent natural disasters, a steady increase in yield, to 2015 the total grain output 2 million 172 thousand tons, representing an increase of 5\%, achieved twelve even the abundance of food".

Accelerate the construction of modern animal husbandry in Shaanxi demonstration zone, initially built in Chengcheng County, Dali County, Linwei District, Baishui County, Iowa Area as the focus of the pig, taking Heyang County as the core area of the cows, taking Fuping County as the core area of the dairy goat and in Pucheng County, Dali County, Linwei District, Tongguan county the four key poultry industry gathering area [5].

Vigorously promote the Shaanxi modern fruit industry strong city construction, five plate prominent apples and pears, grapes, fresh jujube, seasonal fruit characteristics, optimization of industrial structure, accelerate the standardization demonstration garden construction; development of green organic fruit production base, strengthen the production and marketing, to create regional public brand fruit.

Around the idea of "expanding agricultural functions and creating agricultural value", we should vigorously promote leisure agriculture tourism, drive local agricultural products to tourism products and broaden the channels for increasing farmers' income. "Farmers in the new rural areas into tourist attractions, scenic spots, agricultural landscape" is from small to large, from shallow to deep development. 


\subsection{The income of farmers continued to grow rapidly.}

During the "12th Five-Year", the farmers' income in Weinan has entered a rapid growth stage. In 2011 the per capita net income of farmers in our city is 5571 yuan, compared with 2010 growth of 1199 yuan, an increase of 27.4\%; 6602 yuan in 2012, representing a growth of 1031 yuan, an increase of 18.5\%, the growth rate ranked first in the province; 7565 yuan in 2013, representing a growth of 963 yuan, an increase of 14.6\%; 8534 yuan in 2014, representing an annual increase of 969 yuan [6]. An increase of 12.8\%; 8705 yuan in 2015, representing a growth of 969 yuan, an increase of $9.7 \%, 2$ times in 2010.

\subsection{Agricultural science and technology has been popularized, and the level of agricultural mechanized equipment has been greatly improved}

The integration of scientific and technological resources, increase efficiency, and in accordance with the combination of improved matching of agricultural machinery and agronomic principles, carry out major food crop production technology; integration of fine varieties and fertilization, straw utilization, film mulching, yield and other practical wide narrow row spacing cultivation technology; improve grain production seed coverage, contribution rate of agricultural science and technology, farming harvesting mechanization level of application. The coverage rate of the main crops in the city is over 95\%. The field coverage rate of the main crops is 50\%, and the main crops are more than $88 \%$. The conversion rate of the main agricultural products is over $65 \%$. The annual sales value of 388 key leading enterprises in the industrial operation of agriculture in the city was 14 billion yuan. Apple concentrated juice has 280 thousand tons of design and production capacity and 580 thousand tons of fruit storage capacity [8]. It has become the largest apple juice concentrate production base and the largest fruit machinery storage base in the country.

\subsection{The rural reform has been promoted deeply, and the new agricultural management system plays a leading role in the development of Agriculture}

Weinan city in 2014 to start the rural land ownership registration certification work, promote the overall in 8 counties, the remaining 4 counties of the township to promote 1/3. At the end of 2015, 54055 households had issued a certificate of management rights, involving 88 town offices, 278 villages and 768 villagers' groups. To speed up the construction of the new agricultural management system, there are 6269 farmers' professional cooperatives, 1204 family farms, 15560 large farmers, 820 thousand farmers, and about 3200000 acres of agricultural production bases. The new type of profession farmers are constantly emerging. Since 2012, a new type of professional farmers has been trained and the "professional farmer molding project" has been implemented. The total number of 2605 professional farmers in the city was trained by the whole city. Through the identification of 1655 junior high school vocational farmers, 28 of them were senior and 94 were intermediate.

\subsection{Modern agricultural park is flourishing, and the benefit of large-scale agricultural development is remarkable}

In accordance with the idea of industrialization, industrialization and industrialization, Weinan is the first to develop modern agricultural park in the whole province. We must adhere to the construction of modern agricultural parks as an important starting point to push forward the process of agricultural modernization, expand and strengthen the advantageous and characteristic industries, and effectively increase the land output rate, resource utilization rate and labor productivity. In 2015, the modern agricultural park has developed to 346, including 45 provincial level, 125 municipal level, the total area of the park reaches 808 thousand mu, the output value is 9 billion yuan, and the area of [5] is the highest in the whole province. In the park under the guidance of intelligent greenhouse, solar greenhouse, arch advanced agricultural technology studio, spray irrigation, green control, fertilizer integration, bio reactor, advanced agricultural machinery and equipment, food (fruit) - livestock - biogas ecological cycle "and other advanced agricultural production mode is widely used [9]. 


\subsection{The quality and safety of agricultural products are increasingly strengthened.}

We will promote the certification of "three products and one product" and strictly control the quality and safety of agricultural products. We will strictly implement the "three systems" focusing on purchase inspection system, quality traceability system and recall system and strictly control the circulation. We will carry out the special rectification of high-toxic pesticides, agricultural counterfeiting, production bases, major holidays and other special rectifications and strive to improve the four abilities of municipal and county supervision, comprehensive law enforcement, inspection and testing, and the main body of township regulation, actively explore production quasi-, quality tracing, risk assessment, Demonstration counties to create regulatory measures.

\section{Analysis of Disadvantages in the Process of Agricultural Development in Weinan}

Agricultural supply side reforms need is each industry's own adjustment, specialization and scale level, is the main driving force of the industry development in agriculture; in the reform of agricultural industry structure in the supply side under the trend of social development, to ensure the smooth realization of comprehensive agricultural innovation system. Weinan city agricultural work has made some achievements and experience, but the overall pattern of agricultural industry is not strong, the low income of peasants and the Fed has not fundamentally changed. It is mainly manifested in five aspects:

(1) The development of the two or three industry of agriculture is slow, the level of agricultural products processing industry is not high, and the operation scale of agriculture related industry is generally small and scattered. The agricultural industrialization level is not high, the agricultural leading enterprises are not capable of the ability of the farmers in the base zone, and the agricultural product processing industry is still in the primary stage of development. The proportion of the dominant industry is still low, and the multi-function development of agriculture has just started.

(2) The land right work is not one of the progress, the beautiful countryside construction and the land circulation platform are not perfect. The northern city of the country are still a production mode, intensive production has not been part of the land there is no bad farming. As a whole, the scale of agricultural operation is generally small, and the specialized agricultural base is not much.

(3) In the agricultural development of high investment, high pollution and low efficiency of the problem is still more prominent, by means of agricultural production such as chemical fertilizers and pesticides in the low rate of agricultural ecological environment protection pressure big; implementation of factor substitution have demand of agricultural production and operation of the main conditions including the possibility of investment and technological progress brings the additional possibility of creation. With the rapid development of agricultural modernization, great progress has been made in the technology of modern production factors and inputs of machinery, chemical fertilizers and pesticides, seeds, the substitution effect on the traditional elements of land and labor scarcity and increase the cost of more and more strong, effectively promoted the development of agricultural industry structure, improve gradually improved substitution between these elements of agricultural production activity [9]. According to the theory of profit maximization, when the marginal profit of the input factor is greater than the marginal cost, the pursuit of profit makes the producer increase the input of the factor continuously. Therefore, farmers take profit maximization as the basic basis and power for industry selection. The risk restriction and profit attraction caused by factor substitution is an important factor for the formation of factor substitution characteristics in the evolution of agricultural industrial structure. However, excessive use or abuse will lead to the decline of the quality standards of agricultural products, and even the pollution of the land environment, which makes the agricultural ecology unbalance.

(4) Agricultural infrastructure remains weak, irrigation and water conservancy facilities imperfect, Weibei dryland water-saving irrigation facilities to strengthen the ability of coping with disasters; agricultural drought is weak, seriously affected the Akita dryland wheat crops, as many as 1 million 800 thousand acres of upland area accounted for $40 \%$ of the total area of agricultural production, which belongs to the weather. 
(5) The development of e-commerce platform is slow, and the market fluctuation affects the difficulty of realizing the value of agricultural products. We should promote sales of agricultural products through large-scale exhibition and market promotion, but the majority of family growers have been having poor sales channels for agricultural products, and there has been a bumper harvest for farmers. The pain of the people in the valley has been staged in the rural areas of Guanzhong, which has become an obstacle to the development of agriculture.

(6) Weinan City, the agricultural management exists lack of professional and technical personnel, production of single source of information, there is a certain blindness, production concentration, the overall trend of the phenomenon of agricultural personnel quality and the development of modern agriculture needs, there is a big gap between the relevant aspects of the plight of the lack of policy support.

\section{Speed up the Reform of Supply Side, Speed up the Level of Agricultural Modernization and Improve the Competitiveness of Regional Agriculture}

The supply side reform must be based on the agricultural status quo, adjust the industrial structure and product structure with market orientation, strengthen the support of science and technology and scale management, and make the agricultural products more suitable for consumption demand, and change from output to quality and efficiency. Use the method to adjust the adding, subtract, multiply and divide within the agriculture industry, the addition is to solve the unreasonable problem in agricultural development, the development of new industries; subtraction out excess capacity is to improve the innovation ability; multiplication; division is the decentralization of government, enhancing the vitality of the market.

\subsection{In order to promote the construction of the whole town's modern grain base, the "Shaanxi granary" is continuously consolidated.}

Based on the construction of the main grain producing counties at the provincial level, we should focus on the construction of the modern grain base of the whole town and invest 850 million yuan, and build 650 thousand acres of high standard farmland, namely, drought energy irrigation, waterlogging and drainage, Toi and output high, leading the whole Province's grain production. Strengthen the construction of large-scale irrigation projects such as water conservancy reconstruction projects to further consolidate the "big barn in Shaanxi" status, and to adjust for the agricultural industry to make more room for adjustment.

\subsection{Taking the construction of Shaanxi modern animal husbandry demonstration area as the carrier to accelerate the development of modern animal husbandry}

We should carry out the plan for the revitalization of the animal husbandry and continue to promote the construction of the modern animal husbandry demonstration area in Shaanxi. Key construction in Dali, Chengcheng, Pucheng, Linwei, white water as the core, radiation and other counties, the construction of ten million pig industry demonstration zone; in Heyang, Huayin, Dali as the core, radiation Linwei, Pucheng and other counties, the construction of the dairy industry demonstration zone; with "Chinese goat are" Fuping as the core Linwei, Pucheng, radiation and other counties, the construction of dairy goat industry demonstration zone. In Pucheng, Dali, Tongguan as the core, radiation Fuping, Iowa, Linwei and other counties, the construction of million poultry industry demonstration zone; seek a breakthrough in the investment, make full use of the brand of Shaanxi modern animal husbandry industry demonstration zone [10]. Seize the favorable opportunity to speed up from the eastern coastal areas to the Midwest of animal husbandry, Mengniu, Yili, aiming to Wen's other well-known animal husbandry enterprises, formulate preferential policy, carry out and the introduction of a number of industrial investment, high level, large scale of investment, with the strong ability of major projects, accelerate the construction progress fast, enhance the industrial concentration, leading the development of leading industry. 


\subsection{To build Shaanxi modern fruit industry as the grasp of the market, accelerate the upgrading and transformation of the fruit industry}

The fruit, fruit, fruit rich beauty "as the goal, to brand construction, continue to implement the fruit regional public brand strategy, brand promotion work; to speed up the establishment of the Weinan fruit direct image of the store in the major city, and vigorously promote the efficient intensive cultivation techniques of Apple Dwarf rootstock; promote modern fruit industry strong city construction to achieve the scale of operation, the fruit industry, fruit industry to promote the city's transformation and upgrading. We should actively establish the traceability system of fruit quality, perfect the construction of the electronic trading platform, and further strengthen the supervision of the quality and safety of the fruit. The regional public brand as the guide, develop the advantages of the city characteristic fruit standard complex, integrated development of fruit industry resources, create "water apple" and "Pucheng pear", "Dali jujube", "Linwei grapes", "Heyang red" China industry well-known brands, to build Weinan into the "West Guodong" the characteristics of fruit industry strong city and northwest characteristic fruit production base and distribution center.

\subsection{With the construction of modern agricultural park as the support, vigorously promote the development of facility vegetables}

We must adhere to the concept of industrialization, plan agriculture, achieve agricultural industrialization and workshop production, integrate production elements, and achieve industrial transfer and labor force local transfer. We will constantly improve the intensive, specialized, organized and socialized level of agriculture, activate the development of the park and promote the development of modern agricultural parks. Weinan has made great efforts to build a "big vegetable garden" with rich varieties, high quality and quick distribution, the important modern agricultural base in the West and the new city of green food in the whole province.

\subsection{Speed up the process of standardization and brand, and enhance the quality and safety of agricultural products}

Actively guide the agricultural enterprises, farmers' cooperatives, agricultural production and operation of large to carry out the "three a" certification of pollution-free agricultural products, expand the coverage of. Actively implement brand strategy, make big brand, and be strong enterprise. We should strengthen the standardized management of leading enterprises, production bases and agricultural products production, intensify propaganda and implementation of enterprise standards, product standards and production technology regulations, improve product quality, create brand of agricultural products with Weinan characteristics, and create brand leading enterprises. We should speed up the formulation or revision of local agricultural standards and improve the agricultural standard system. Focusing on gardening standard garden and livestock and poultry breeding standard demonstration farm, we should speed up the construction of quality inspection institutions for agricultural products, improve the quality and safety supervision team of agricultural products, and improve the quality and safety supervision system of agricultural products. We should establish and improve the supervision system of agricultural products quality and safety risk monitoring, producing areas, market access, quality traceability, delisting, and so on, and strengthen the supervision of agricultural inputs. We should improve the emergency emergency plan for the emergency of the quality and safety of agricultural products, and establish an emergency response network with rapid response and cross zone linkage.

\subsection{Promoting the integration and development of agriculture related and two or three production}

Taking market demand as the guidance, we should focus on supporting and strengthening the leading enterprises of agricultural industrialization, and promote the transformation of agricultural products from primary processing to intensive processing. The transformation from traditional processing technology to advanced and applicable technology will focus on building nine industrial processing chains, including grain, oil, feed, pork products, dairy products, poultry products, 
aquatic products, forest products and vegetable processing. The introduction of advanced technology and management methods of logistics services, warehousing, transportation, packaging development, agricultural services, agricultural sales for the agricultural logistics service system support, the establishment of smooth, composite and efficient agricultural logistics service network, to achieve effective docking of agricultural production and modern agricultural production processing three.

\section{References}

[1] Zhang L Y, Finance D O. To Promote the Development of Inclusive Finance in Rural Areas by Structural Reform of Agricultural Supply Side__ Take Jilin Province as an Example[J]. Journal of Changchun Finance College, 2017.

[2] Xin He, Yun-Ling Hu, Ya-Nan Lu, et al. Countermeasure of Tea Industry Development in Changsha County Based on Supply Side View[J]. Journal of Anhui Agricultural Sciences, 2017.

[3] Liu L Y, Wei S C, Liu Y D. The Demand and Training Mode of Agricultural Related Professionals in Secondary Vocational Schools under the Background of Agricultural Transformation[J]. Journal of Anhui Agricultural Sciences, 2017.

[4] Zhao L. The Focal Point and Implementation Path of Supply Side Reform in Rural Areas of China[J]. Reformation \& Strategy, 2017.

[5] Zhao X T, Government H T. Developing the flower industry in the cold region and promoting the adjustment of agricultural structure[J]. Heilongjiang Science, 2017.

[6] Xin G, Yang C, Shao J, et al. Optimization and demonstration of land consolidation technical system in mountainous and hilly region based on farmland transfer[J]. Transactions of the Chinese Society of Agricultural Engineering, 2017, 33(6):246-256.

[7] Yan Yu. Analyze the Mechanism of Establishing Regional Brand Competitive Advantage of Chinese Characteristic Agricultural Products Under the Background of Supply Side Structure Reform[J]. 2017(eced).

[8] Gao M F. Problems and Countermeasures of Agricultural Industrial Structure Adjustment in Weinan City[J]. Journal of Weinan Normal University, 2015.

[9] Xu H S, Xu Z X, Liu P. [Estimation of nonpoint source pollutant loads and optimization of the best management practices (BMPs) in the Zhangweinan River basin]. [J]. Huan jing ke xue= Huanjing kexue, 2013, 34(3):882.

[10] Zhou Li. Path and Enlightenment of Optimization and Upgrading of Agricultural Structure by the Leading of Characteristic Agriculture: Taking Luoyang City as an Example[J]. Areal Research \s\&\sdevelopment, 2016. 